Хасанова Г.Р., Ямалов С.М., Лебедева М.В., Голованов Я.М.

es flexibility and improves performance of ecological niche modeling // Ecography. 2018. Vol. 41. P. 291-307.

18. Соломаха А.В. Синтаксономія сегетальної рослинності Північного Причорномор"я // Украинский ботанический журнал. 1988. № 45 (2). С. 27-33.

19. Соломаха А.В. Синтаксономія рослинності України. Трете наближення. Київ: Фітосоціоцентр, 2008. 296 с.

20. Гельтман Д.В., Медведева Н.А. Euphorbia glyptosperma (Euphorbiaceae) - новый чужеродный вид для флоры России // Новости систематики высших растений. 2017. № 48. С. 131-135.

21. Мулдашев А.А., Абрамова Л.М., Голованов Я.М. Конспект адвентивных видов растений Республики Башкортостан. Уфа: Башк. энцикл., 2017. 168 с.

Статья публикуется при поддержке РФФИ (проекты № 17-44-020402 p_a, № 19-016-00135) u средств государственного бюджета (№ $A A A A-$ A18-118011990151-7).

\title{
NEW ASSOCIATION OF WEED VEGETATION IN THE SOUTHERN URAL
}

(C) 2019

Khasanova Gulnaz Rimovna, candidate of biological sciences, associate professor of Soil Science, Botany and Selection Department

Bashkir State Agrarian University (Ufa, Russian Federation)

Yamalov Sergey Maratovich, doctor of biological sciences,

leading researcher of Wild-Growing Flora and Herbasceous Plants Introduction Laboratory

Lebedeva Maria Vladimirovna, candidate of biological sciences, senior researcher of Tropical and Subtropical Plants Group

Golovanov Yaroslav Mikhailovich, candidate of biological sciences, senior researcher of Wild-Growing Flora and Herbasceous Plants Introduction Laboratory

South-Ural Botanical Garden-Institute of the Ufa Federal Research Centre of Russian Academy of Sciences (Ufa, Russian Federation)

Abstract. A geobotanic survey was carried out and the diversity of weed communities of the steppe zone of the Orenburg and Ilek administrative Districts of the Orenburg Region was revealed. As a result of the synthaxonomic analysis, the studied communities are assigned to the new association Amarantho blitoidis-Lactucetum tataricae ass. nov. hoc loco in the system of units of ecological-floristic classification of Eurasia vegetation. The association united weed communities of spring wheat, sunflower, less often - rye, barley, corn and sorghum, emerging mainly on welldrained swollen soils in the flood of the Ural River. The cenophlora is characterized by the presence of bondate and optional psammophytes - Chondrilla brevirostris, Helichrysum arenarium, Ceratocarpus arenarius, etc. The communities of the association occupy an extreme position on gradients of aridity and moisturization factors among other weed vegetation communities of the Southern Ural. The North American alien species Euphorbia glyptosperma Engelm has been discovered for the first time in the Orenburg Region (subgenus Chamaesyce Raf., section Anisophyllum Roep.). Currently this species is expanding its range from the south of the Russian Federation. Other alien plants have been noted as part of the communities: Amaranthus blitoides S. Wats., A. retroflexus L., Conyza canadensis (L.) Cronq., Xanthium album (Widder) Scholz et Sucopp.

Keywords: weed vegetation; weed species; weed communities; agrocenosis; syntaxonomy; Southern Ural; Orenburg Region; edaphic and climatic factor; agrocenotic factor; aridity; alien species; Euphorbia glyptosperma; DCAordination; steppe zone.

\section{ОЦЕНКА ИЗМЕНЕНИЯ ФИТОТОКСИЧНЫХ СВОЙСТВ НЕФТЕЗАГРЯЗНЕННЫХ ПОЧВ ПО ПОКАЗАТЕЛЯМ ВСХОЖЕСТИ И ДЛИНЫ ПРОРОСТКОВ LEPIDIUM SATIVUM L. ПОСЛЕ ЭЛЕКТРОХИМИЧЕСКОЙ ОЧИСТКИ}

(C) 2019

Шулаев Николай Сергеевич, доктор технических наук, профессор, заведующий кафедрой информатики, математики и физики

Пряничникова Валерия Валерьевна, кандидат технических наук, доцент кафедры общей химической технологии

Кадыров Рамиль Римович, кандидат технических наук, доцент кафедры автоматизированных технологических и информационных систем

Быковский Николай Алексеевич, кандидат технических наук,

доцент кафедры автоматизированных технологических и информационных систем

Даминева Раиса Мухаметовна, кандидат экономических наук, заведующий кафедрой гуманитарных наук Филиал Уфимского государственного нефтяного технического университета в г. Стерлитамаке

(2. Стерлитамак, Республика Башкортостан, Российская Федераиия)

Аннотация. Разнообразные варианты технологии электрической обработки почвы применяются для решения экологических, технологических и агромелиоративных задач. В данной статье оценивается изменение 
свойств загрязненной почвы при очистке за счет пропускания через нее токов малой величины. Приводятся результаты исследования изменения токсичных свойств почвы, загрязненной нефтью и минерализованными пластовыми водами в результате добычи нефти, после проведения электрохимической очистки. Для интегральной оценки опасных свойств загрязненной почвы после электрообработки применяется методика биотестирования с кресс-салатом (клоповником посевным, Lepidium sativum L.). Данный биологический тестобъект обладает высокой отзывчивостью к присутствию поллютантов в почвенной и водной среде, неприхотливостью и способностью к быстрому прорастанию. Ключевыми параметрами при проведении исследования являются процент всхожести семян и общая длина проростков (подземной и надземной частей). Проведен статистический анализ полученных данных, а также сравнение фитотоксичности загрязненной почвы до и после электрохимической очистки. Из анализа экспериментальных данных можно сделать вывод о потенциальной пригодности рассматриваемого метода для полноценного восстановления естественных растительных сообществ на месте загрязнения, а также для проведения комплексных работ по фиторемедиации.

Ключевые слова: электрохимическая очистка; обессоливание; электроды; электрический ток; нефтезагрязненные почвы; нефтепродукты; пластовые воды; биотестирование; фитотоксичность; тест-объект; кресссалат; всхожесть; длина проростков; коэффициент корреляции; восстановление; фиторемедиация.

\section{Введение}

Методы обработки почвы электрическим током могут применяться для решения различных техникоэкологических задач. Это предпосевная обработка почв малыми токами, обработка грунтов нефтедобывающих районов с целью увеличения продуктивности пласта и восстановления скважин, агромелиоративные технологии обессоливания сельскохозяйственных земель, а также очистка загрязненных почв промышленных и городских территорий.

В последнем случае методы электрохимической или электрокинетической очистки незаменимы для разложения и удаления загрязняющих веществ, проникших в грунт на большую глубину и для очистки высокодисперсных почв [1, с. 14]. Технология электрохимической очистки позволяет восстанавливать почвы, загрязненные тяжелыми металлами, фенолами, радионуклидами, солями и некоторыми органическими веществами [2, с. 227-228]. Это обусловливает потенциальную значимость использования электрообработки при очистке почв, загрязненных в результате добычи нефти, когда в грунт могут одновременно попадать и нефтепродукты, и минерализованные пластовые воды. Эффективность применения и некоторые технические особенности электрохимической очистки нефтезагрязненных почв рассматривалась авторами в ряде публикаций [3-5].

Постоянное электрическое поле, приложенное к водонасыщенному грунту или почве, вызывает протекание электрохимических и электрокинетических процессов. К ним относятся: электролиз, электрофлотация, электрокоагуляция, электродеструкция, электрохимическое обеззараживание, ионный обмен, электрохимическое окисление [6, с. 344] и выщелачивание, электродиализ, а к электрокинетическим электроосмос [7, с. 137], электрофорез и электромиграция [8, с. $120 ; 9$, с. 348-351]. Электрокинетические процессы вызывают перемещение загрязняющих веществ по направлению к противоположно заряженным электродам (при этом частицы нефти, окруженные жидкой фазой, будут перемещаться к катоду), откуда производится их извлечение с последующим разделением и утилизацией. В то же время пропускание токов малой величины позволяет проводить окисление некоторых веществ (например, нефтяных углеводородов) до более простых, а при создании оптимальных условий - достигать полной минерализации. Кроме перечисленных явлений, может происходить электростимуляция аборигенных микроорганизмов [10, с. 112]. Метод может использоваться для очистки не только почв, но и подземных вод [11, с. 336-340].

\section{Цель и объекты исследования}

Важнейшей задачей при применении электрообработки почв является оценка возможных негативных эффектов, которые могут возникнуть из-за побочных продуктов физико-химических реакций, отличающихся в почвенной среде особой сложностью. Для того, чтобы избежать вторичного загрязнения почвенной среды, необходимо уделять большое внимание мониторингу изменения физико-химических и токсикологических почвенных характеристик.

С этой целью были проведены исследования фитотоксичных свойств почвы, загрязненной в результате нефтедобычи нефтью и пластовыми водами, после проведения их электрохимической очистки. Биотестирование осуществлялось с применением высокочувствительного вида растений - кресс-салата $(L e$ pidium sativum $\mathrm{L}$.).

Биотестированием является процедура установления токсичности среды с помощью тест-объектов, сигнализирующих об опасности независимо от того, какие именно вещества и в каком сочетании вызывают изменения их жизненно важных функций [12, c. 123].

Кресс-салат отличается быстрым прорастанием семян и почти стопроцентной всхожестью, которая заметно уменьшается в присутствии поллютантов [13, с. 108]. Достоинством этого растения как биологического тест-объекта является высокая чувствительность, проявляющаяся в замедлении роста побегов и корней.

Электрохимической обработке подвергалась модельная почва, содержавшая 1100 мг/кг нефти и 408900 мг/кг пластовых вод (т.е. водного раствора солей) с преобладанием хлоридов натрия, кальция и магния [14, с. 48]. Такое содержание загрязняющих веществ соответствует почве, отобранной ранее на месте разлива, произошедшего на нефтяном месторождении при добыче. Свойства нефти приведены в таблице 1 .

\section{Материалы и методика исследований}

Электрообработка почвы проводилась в течение 90 минут при плотности тока $340,4 \mathrm{~A} / \mathrm{M}^{2}$ (сила тока 0,8А). Содержание нефтепродуктов после проведения очистки определялось методом ИК-спектрометрии [15] и составило 279,8 мг/кг. Общая минерализация почвы снизилась более чем в 2 раза. 
Шулаев Н.С., Пряничникова В.В., Кадыров Р.Р., Быковский Н.А., Даминева Р.М.

Таблица 1 - Физико-химические свойства нефти

\begin{tabular}{|l|c|}
\hline \multicolumn{1}{|c|}{ Наименование показателя } & Значение \\
\hline Температура начала кипения компо- & \\
нентов, \%: & \\
- до $120^{\circ} \mathrm{C}$ & 8,0 \\
- до $200^{\circ} \mathrm{C}$ & 4,5 \\
- до $300^{\circ} \mathrm{C}$ & 13,5 \\
\hline Вязкость кинематическая, сСт: & \\
- при $0^{\circ} \mathrm{C}$ & 73,83 \\
- при $20^{\circ} \mathrm{C}$ & 21,13 \\
- при $40^{\circ} \mathrm{C}$ & 10,72 \\
\hline Содержание в сырой нефти, \% масс: & \\
- сера & 2,95 \\
- парафины & 3,1 \\
- смолы & 14,6 \\
- механические примеси & 0,0076 \\
\hline Плотность, г/см ${ }^{3}$ & 0,880 \\
\hline
\end{tabular}

Для анализа влияния электрохимической обработки использовались модельная почва на основе чернозема обыкновенного, загрязненная нефтью и пластовыми водами, приготовленная в соответствии с составом почвы с нефтяного месторождения. Также анализировались смеси указанной модельной почвы с чистой почвой, обладающей аналогичными характеристиками («разбавления» 2-, 4-, 8-, 16-, 32кратные).

Биотестирование загрязненной почвы после электрохимической очистки с применением кресс-салата проводилось по стандартной методике [16]. Методика включает следующие основные этапы: пластиковые стаканчики наполняют 100 г анализируемой почвы, куда помещают по 20 семян на глубину 1-1,5 см. Для контроля использовалась незагрязненная почва. Каждая проба поливается дистиллированной водой. Подготавливается по три пробы для каждого типа почвенной смеси. Продолжительность опыта составляла семь дней, после чего производился подсчет количества проросших семян и измерение длины проростков. Извлечение и разделение корневой системы кресс-салата производилось при поливе водой почвенной пробы и последующем малоинтенсивном осторожном промывании в специально подготовленной неглубокой емкости во избежание их повреждения и разрыва. Далее осуществлялась статистическая обработка данных с использованием стандартных методов и их анализ.

\section{Результаты исследований и их обсуждение}

Подсчет количества проросших семян кресссалата позволил установить зависимость между величиной процента всхожести семян и разбавлением пробы (соответственно, и концентрацией загрязняющих веществ), которая описывается уравнением:

$$
y=64,29+0,779 x .
$$

При этом коэффициент корреляции составляет 0,69, что свидетельствует о прямой достоверной зависимости.

Результаты статистической обработки данных по всхожести семян были представлены в графическом виде при помощи специализированной компьютерной программы (рис. 1).

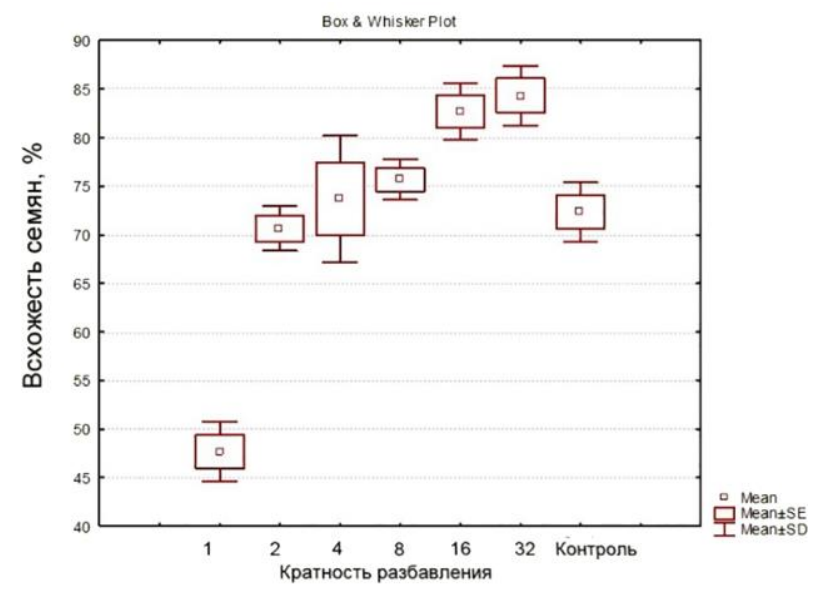

Рисунок 1 - Результаты статистической обработки данных по всхожести семян кресс-салата

Всхожесть семян в контроле (чистой почве) составляет 72,3\%. Как видно из диаграммы, всхожесть превышает контрольные значения, начиная с 4-х кратного разбавления $(73,67 \%)$, при 2-х кратном разбавлении наблюдается незначительный подавляющий эффект $(70,67 \%)$. При этом в загрязненной почве, необработанной электрическим током, семена вовсе не прорастали, а при двухкратном ее разбавлении с чистой почвой всхожесть составляла 16,7\%.

В неразбавленной почве после обработки (нативная среда) всхожесть составляет примерно $48 \%$.

Далее производилось определение средней длины проростков для каждого типа почвенной смеси (т.е. каждого разведения). Статистическая обработка полученных данных позволила получить уравнение зависимости длины проростков от величины разбавления, которая принимает вид:

$$
y=52,55+0,327 x .
$$

В этом случае коэффициент корреляции составил 0,89. Это свидетельствует о том, что обнаруженная зависимость является прямой достоверной. Увеличение длины проростков по сравнению с контрольными пробами при 8-32-х кратном разведении может объясняться тем, что остаточные небольшие количества углеводородов служат источником органического вещества для растений.

Анализ данных по длине проростков кресс-салата был представлен на следующей диаграмме (рис. 2).

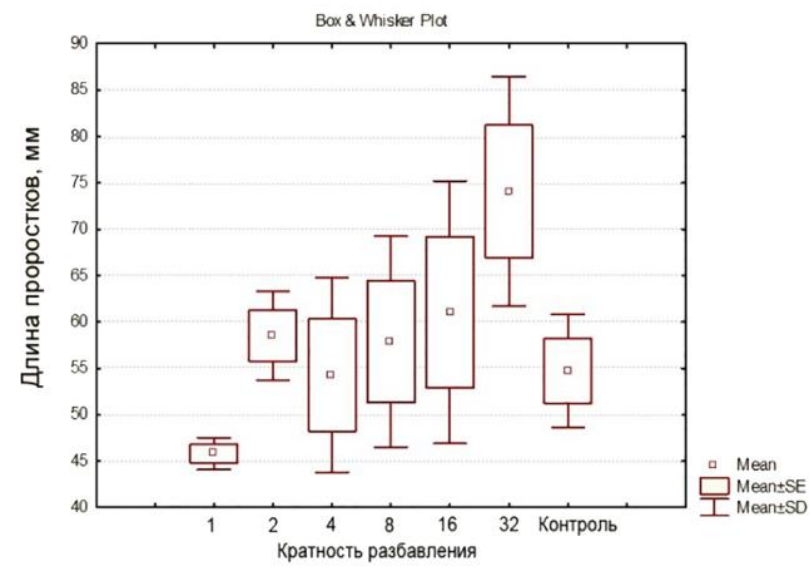

Рисунок 2 - Результаты статистической обработки данных по длине проростков кресс-салата 


\section{Заключение}

Как показали полученные данные, после электрохимической очистки токсичность пробы снижается по сравнению с необработанной почвой. Согласно методике, токсичность - хроническая. Всхожесть семян в загрязненной почве после очистки составила $47,67 \%$, а в загрязненной почве до очистки - $0 \%$ (что соответствует острой токсичности среды).

Результаты проведенного анализа подтверждают, что электрохимическая очистка нефтезагрязненных почв с использованием малых токов способствует уменьшению токсичных свойств почв, не приводя к вторичному загрязнению, что позволяет использовать данный метод для эффективной ремедиации территорий нефтедобычи с восстановлением флоры. Кроме того, электрохимическая очистка может использоваться до проведения фиторемедиации грунтов в качестве подготовительного этапа [17].

\section{Список литературы:}

1. Королев В.А. Электрохимическая очистка грунтов от экотоксикантов: итоги и перспективы // Вест. Московского ун-та. Геология. 2008. № 1. С. 13-20.

2. Королев В.А. Электрохимическая очистка загрязненных грунтов // Геоэкология. Инженерная геология. Гидрогеология. Геокриология. 2003. № 3. С. 226-236.

3. Pryanichnikova V.V., Shulaev N.S., Bykovsky N.A., Kadyrov R.R. The Electrochemical Method of OilContaminated Soil Remediation // Key Engineering Materials. 2017. Vol. 743. P. 314-318. DOI: 10.4028/www. scientific.net/KEM.743.314.

4. Пряничникова В.В., Шулаев Н.С., Быковский Н.А., Кадыров Р.Р. Особенности электрохимической очистки различных типов почв от нефтепродуктов // Бутлеровские сообщения. 2018. Т. 53, № 3. С. 124-129.

5. Пряничникова В.В., Шулаев Н.С., Быковский Н.А., Кадыров Р.Р. Расчет электрических параметров при электрохимической очистке нефтезагрязненных грунтов // Фундаментальные исследования. 2018. № 12-2. С. 208-212.

6. Ferrarese E., Andreottola G. Application of Electrochemical techniques for the remediation of soils contaminated with organic pollutants // Proceedings of the annual international conference on soils, sediments, water and energy. 2010. Р. 342-372.

7. Простов С.М. Физические предпосылки очистки грунтовых массивов от загрязнений электрохимическим методом // Вестник Кузбасского государ- ственного технического университета. 2014. № 2 (102). C. 136-139.

8. Acar Y.B., Gale R.J., Alshawabkeh A.N. Electrokinetic remediation: basics and technology status // Journal of Hazardous Materials. 1995. № 40. P. 117-137.

9. Ступин Д.Ю. Загрязнение почв и новейшие технологии их восстановления: учеб. пособие. СПб.: Лань, 2009. 432 c.

10. Chirakkara Reshma A., Cameselle C., Reddy Krishna R. Effect of electrokinetic enhancement on phytoremediation of soils with mixed contaminants // Electrokinetic remediation (EREM2014): Book of abstracts. Malaga, 2014. P. 112-113.

11. Lynch R. Electrokinetic Barriers for Preventing Groundwater Pollution. Electrochemical remediation technologies for polluted soils, sediments and groundwater. 2009. P. 335-357.

12. Заболотских В.В., Васильев А.В. Мониторинг токсического воздействия на окружающую среду с использованием методов биоиндикации и биотестирования: монография. Самара: Изд-во Самарского научного центра РАН, 2012. 233 с.

13. Овсянникова И.В. Новые методики биотестирования с использованием растений кресс-салата (Lepidium sativum) для экологического контроля окружающей среды // Системы контроля окружающей среды. 2016. Т. 2016. С. 108.

14. Пряничникова В.В., Шулаев Н.С., Быковский Н.А., Кадыров Р.Р. Электрохимическая очистка нефтезагрязненных грунтов // Бутлеровские сообщения. 2016. Т. 47, № 7. С. 47-51.

15. ПНД Ф 16.1.41-04 «Количественный химический анализ почв. Методика выполнения измерений массовой концентрации нефтепродуктов в пробах почв гравиметрическим методом». М., 2004. $11 \mathrm{c.}$

16. ФР.1.39.2016.24117 Методика определения токсичности почв по всхожести семян и измерению средней длины проростка кресс-салата (Lepidium sativum). М.: ФГБОУ ВО БГУ, 2015. 22 с.

17. Шулаев Н.С., Пряничникова В.В., Кадыров Р.Р., Быковский Н.А. Фиторемедиация нефтезагрязненных почв // Бутлеровские сообщения. 2016. Т. 47, № 8. C. $133-138$.

Исследование выполнено при финансовой поддержке РФФИ в рамках научного проекта № 1829-24041.

\section{ASSESSMENT OF CHANGES IN THE PHYTOTOXIC PROPERTIES OF OIL-CONTAMINATED SOILS IN TERMS OF GERMINATION AND SEEDLINGS LENGTH OF LEPIDIUM SATIVUM L. AFTER ELECTROCHEMICAL CLEANING}

Shulaev Nikolay Sergeevich, doctor of technical sciences, professor, head of Informatics, Mathematics and Physics Department

Pryanichnikova Valeria Valeryevna, candidate of technical sciences, associate professor of General Chemical Engineering Department

Kadyrov Ramil Rimovich, candidate of technical sciences, associate professor of Automated Technological and Information Systems Department

Bykovskiy Nikolay Alekseevich, candidate of technical sciences, associate professor of Automated Technological and Information Systems Department

Damineva Raisa Mukhametovna, candidate of economical sciences, head of Humanities Department Sterlitamak Branch of Ufa State Petroleum Technological University (Sterlitamak, Republic of Bashkortostan, Russian Federation)

Abstract. Different variants of electric treatment technology are used to solve environmental, technological and agro-melioration problems. This paper assesses the change in the properties of contaminated soil during cleaning by 
passing small amperage through it. The paper contains the results of the study of changes in the toxic properties of soil contaminated with oil and mineralized formation water at oil production after electrochemical treatment. A biotesting technique with Lepidium sativum L. is used for an integrated assessment of the hazardous properties of contaminated soil after electrical treatment. This biological test object has a high responsiveness to the presence of pollutants in soil and water, as well as the ability to rapidly germinate. The main parameters during the study are the percentage of seed germination and the total length of seedlings (underground and aboveground parts). A statistical analysis of the data is carried out. The phytotoxicity of contaminated soil is compared before and after cleaning. The conclusion is drawn about the potential suitability of this method for the full restoration of natural plant communities at the pollution territory, as well as for conducting complex phytoremediation.

Keywords: electrochemical cleaning; desalination; electrodes; electric current; oil-contaminated soil; oil products; formation water; biotesting; phytotoxicity; test object; watercress; germination; length of seedlings; correlation coefficient; recultivation; phytoremediation.

$* * *$

УДК 581.91

DOI 10.24411/2309-4370-2019-14119

Статья поступила в редакцию 01.09.2019

\section{РЕДКИЕ И НУЖДАЮЩИЕСЯ В ОХРАНЕ ВИДЫ РАСТЕНИЙ КАМЕНИСТЫХ СТЕПЕЙ ЮЖНОГО И СРЕДНЕГО УРАЛА}

(C) 2019

Ямалов Сергей Маратович, доктор биологических наук, ведущий научный сотрудник лаборатории дикорастущей флоры и интродукции травянистых растений

Лебедева Мария Владимировна, кандидат биологических наук, старший научный сотрудник группы тропических и субтропических растений

Голованов Ярослав Михайлович, кандидат биологических наук,

старший научный сотрудник лаборатории дикорастущей флоры и интродукции травянистых растений

Петрова Мария Владимировна, аспирант

лаборатории дикорастущей флоры и интродукции травянистых растений

Южно-Уральский ботанический сад-институт Уфимского федерального исследовательского ичентра РАН (2. Уфа, Российская Федераиия)

Аннотация. Выявлен редкий компонент флоры каменистых степей Южного и Среднего Урала и приуроченность редких и нуждающихся в охране видов к разным их типам. Установлено произрастание 154 редких и нуждающихся в охране вида, реликтов и эндемиков, что составляет 20,8\% всей ценофлоры каменистых степей региона. В их числе 18 видов, включенных в Красную книгу РФ, а также 98 видов, занесенных в региональные Красные книги. Выявлено произрастание 34 эндемичных видов, относящихся преимущественно к группе скальных и петрофитностепных эндемиков. Реликтовая флора насчитывает 42 вида. Большая часть из них (25 видов) относится к голоцену, группа плейстоценовых реликтов представлена 13 видами. Анализ ценофлоры позволил выявить особенности распределения редких видов по сообществам, характеризующим разные типы местообитаний. Наибольшая доля редких видов отмечена в сообществах юга лесостепной зоны на известняковых субстратах (более $30 \%$ - 81 вид). Полученные данные подтверждают высокую природоохранную значимость петрофитных степей Южного и Среднего Урала и могут служить основой для формирования комплексной стратегии охраны этих сообществ.

Ключевые слова: петрофитные степи; каменистые степи; флора; редкие виды; петрофитностепные эндемики; реликты; биоразнообразие; местообитание; сообщества; растительность; фитоценон; Красная книга; Республика Башкортостан; Южный Урал; Средний Урал.

Каменистые (петрофитные) степи Южного и Среднего Урала традиционно представляют интерес для исследователей флоры и растительности [1-4]. Уникальность флоры каменистых субстратов, насыщенной степными, реликтовыми и эндемичными, видами отмечали Н.П. Крылов [5], С.И. Коржинский [6]. В период активного сельскохозяйственного освоения (60-80-е годы XX века) произошло резкое сокращение площади зональных степей. Большинство степных массивов на плакорах и равнинных территориях были освоены под пашню. Степные сообщества сохранились преимущественно на возвышенных формах рельефа и чаще всего связаны со склоновыми каменистыми местообитаниями. Сообщества каменистых степей на Урале стали своеобразными рефугиумами степной флоры и растительности региона
[7]. На современном этапе эти сообщества имеют высокое природоохранное значение как носители уникального биоразнообразия, их ценофлора включает большое число редких и нуждающихся в охране видов, реликтов и эндемиков.

На сегодняшний день собран большой фактический материал, который насчитывает 852 геоботанических описаний каменистых степей региона. Данная выборка достаточно репрезентативно представляет этот тип сообществ на широтном градиенте более 900 км, охватывающем Средний и Южный Урал и сопредельные территории на территориях Республики Башкортостан (РБ), Свердловской (СО), Челябинской (ЧО) и Оренбургской области (ОО).

Цель настоящей работы: выявление редкого компонента флоры каменистых степей Южного и 